\title{
Effect of Black Soybean (Glycine max (L.) Merrill) Flour Intervention on Blood Pressure, Fasting Blood Glucose Level and Lipid Profile of Hypertensive Postmenopausal Women
}

\author{
Neetu Dobhal ${ }^{*}$ and Rita Singh Raghuvanshi
}

Department of Foods and Nutrition, College of Home Science, G. B. Pant University of Agriculture \& Technology, , Pantnagar (263145), District- Udham Singh Nagar, Uttarakhand, India

*Corresponding author

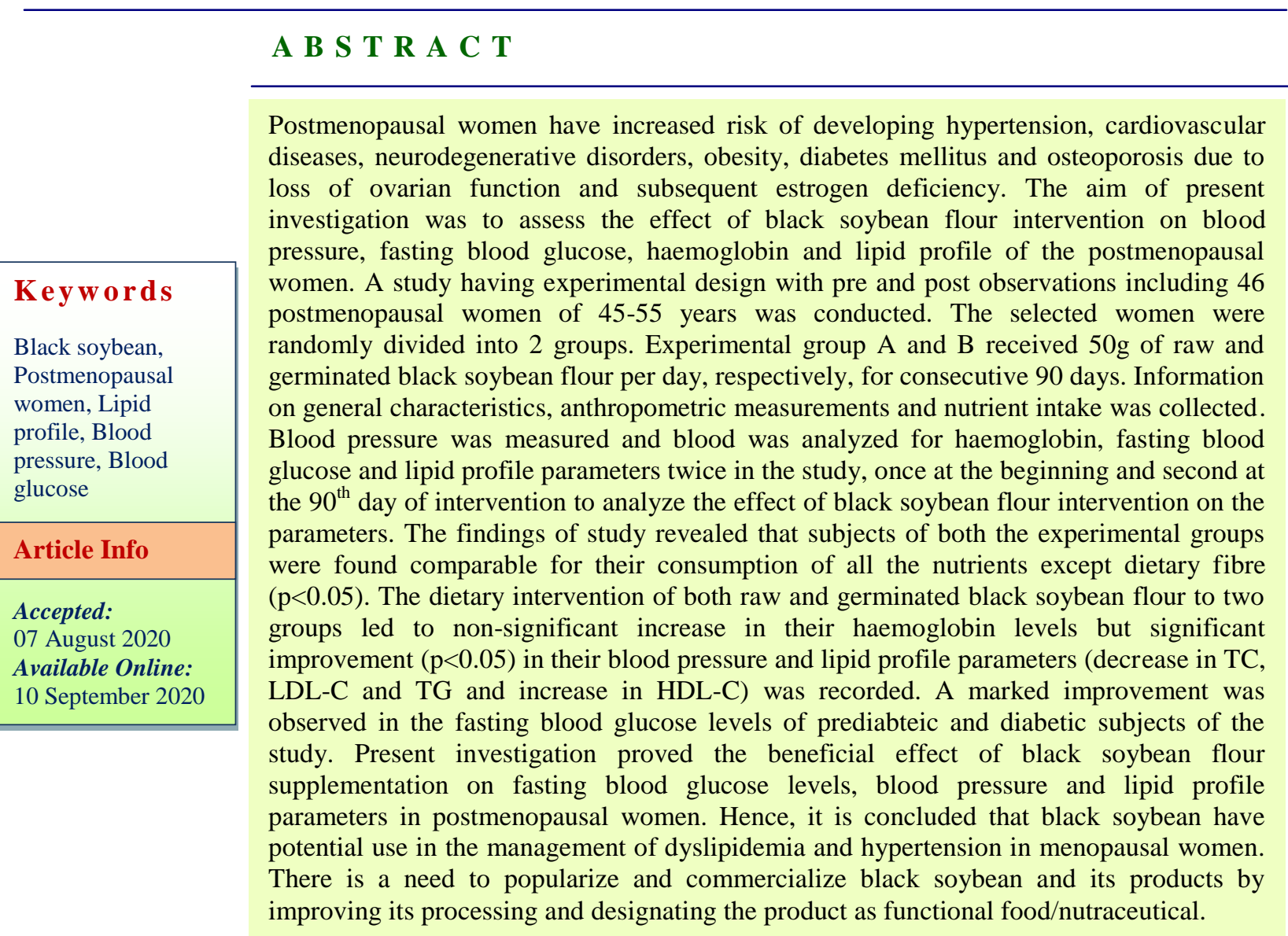




\section{Introduction}

Non-communicable diseases are the vital causes of morbidity and mortality in India and hypertension is one of the most important risk factors for CVD and non-communicable diseases (Gupta and Xavier, 2018). Abnormal blood concentrations of lipids i.e. dyslipidemia is one of the most significant modifiable risk factors for cardiovascular disease. Although medicines are effective in reducing low-density lipoprotein cholesterol levels, the best approach for prevention and management of CVD is to modify dietary and lifestyle patterns (Vanessa et al., 2014). Hypertension is directly responsible for $57 \%$ strokes and $24 \%$ of all CHD-related deaths in India (Gupta et al., 2018). More that $25 \%$ of adult female population is hypertensive worldwide (Kearney et al., 2005), among which postmenopausal women are at higher risk of cardiovascular problems (Bhagat et al., 2010; Tandon et al., 2010).

Menopause is a natural transition experienced by every woman and occurs when the ovaries stop releasing egg every month and menstruation stops. It indicates the end of reproduction ability of woman. Loss of ovarian function and subsequent estrogen deficiency increases the risk of developing hypertension (Zhoua et al., 2015), cardiovascular diseases, neurodegenerative disorders, obesity, diabetes mellitus and osteoporosis (Chedraui et al., 2010).

Postmenopause is the time after menopause and lasts for more than one third of women's life. Karita et al., (2008) and Hong and Kim (2017) reported the higher prevalence of dyslipidemia in the postmenopausal women than the premenopausal women. Women's health problem during postmenopause changes her life style in various ways like physical, emotional, social and financial quality of life. In the developed countries, management of menopause is routine practice (Deviga et al., 2016) but in India, it still needs special attention and treatment.

Soybean being rich in phytoestrogens might play an important role in the treatment of menopausal health problems. A study reported that is flavones present in soybeans, have both estrogen and antiestrogen action, cell proliferation inhibition property and serum cholesterol reducing ability, which are relevant attributes to reduce the risks of noncommunicable chronic diseases such as CVDs, cancer, osteoporosis, and menopausal symptoms (Penha et al., 2007).

Various studies have reported the beneficial role of soybean consumption in the management of dyslipidemia (Yang et al., 2017), atherosclerosis (Cano et al., 2010) and hypertension (Kou et al., 2017) by using either the soy extracted isoflavones or isolated soy protein.

Black soybean (Glycine max (L.) Merrill), is one of the major crops grown in 5734 hectare area of Uttarakhand, a hilly state of India, with the productivity and yield of $9.82 \mathrm{q} / \mathrm{ha}$ and 5636t, respectively (Hipparagi et al., 2017). It is locally known as Bhatt. Chen et al., (2017) and Ganeshan and Xu (2017) have reported the antioxidant, hypolipidemic and estrogenic activity of black soybean.

Despite of having numerous health benefits, black soybean is consumed on a very limited scale in India. This may be attributed to its black colour and beany flavour which is generally not liked by people. Therefore, the present study was undertaken to assess the therapeutic effect of whole black soybean flour intervention in improving blood pressure, fasting blood glucose levels and lipid profile of hypertensive postmenopausal women. 


\section{Materials and Methods}

\section{Locale and year}

The present investigation was conducted in Udham Singh Nagar district of Uttarakhand in 2018.

Material procurement and flour development

The VL-63 variety of black soybean was obtained from Tarai Development Corporation (TDC), Haldi, District U.S. Nagar (Uttarakhand). The seeds of black soybean were cleaned manually to remove foreign materials, broken and immature soybeans. Two types i.e. raw and germinated flours were developed from black soybean. Germinated flour was developed by washing of black soybeans in clean water, followed by overnight soaking and draining. Germination was carried out for next 72 hours at $32 \pm 2^{\circ} \mathrm{C}$ in incubator. Germinated grains were oven-dried at $65 \pm 2^{0} \mathrm{C}$ till completely dried, followed by grinding into flour. Flour was sieved through 60 mesh sieve and stored the flour in dry and air tight containers for further use.

\section{Subject selection}

Subjects were included in the study on the basis of criteria like age within 45-55 years with absence of menses (for at least 12 months but not more than 5 years), with diagnosed hypertension $(\mathrm{BP} \geq 120 / 80 \mathrm{mmHg}$ ) and willing to participate in present research. Women receiving hormone replacement therapy for treatment of menopausal symptoms or with history of any degenerative diseases such as stroke, congestive heart failure, malignant tumours, myocardial infarction and hepatitis were excluded. Women with known allergy to soybean and with habit of drinking alcohol and cigarette smoking were also excluded.

\section{Sample size estimation}

Sample size for the present research was calculated using the formula given by Dhulkhed et al., (2008) at $80 \%$ precision and 95\% level of confidence, which came to 46 . For selection of subjects, a list of total 157 postmenopausal women was prepared from the localities of district Udham Singh Nagar, Uttarakhand and they were assessed for their eligibility in the study. Out of 157, 27 women were excluded as they didn't meet the inclusion criteria. Among remaining 130, fifty women were randomly selected using random number tables (Fig. 1).

\section{Ethical considerations}

Subjects were explained about the objectives of study and a fully informed written consent was taken from each subject. A formal approval was also taken from the University Ethics Committee for Human Research (UECHR) G.B. Pant University of Agriculture and Technology, Pantnagar, Uttarakhand.

\section{Study tool}

A structured interview schedule was developed for obtaining information on sociodemographic parameters like religion, education, occupation, family type and family size etc. Anthropometric measurements included height and weight measurement and BMI was calculated. Information on physical workout of subjects and family history of the hypertension, presence of diabetes mellitus, medication and treatment was also collected, using a structured questionnaire. Nutrient intake of the subjects was assessed using 24hour dietary recall method. Blood pressure (BP) of subjects was taken with an automated blood pressure device twice during the study i.e. before and after the intervention period. Subjects were classified in various categories 
of hypertension based on their mean blood pressures using the classification given by Joint National Committee (JNC) on Hypertension, 2003 (Chobanian et al., 2003).

\section{Biochemical analysis}

The present study was an experimental study where baseline parameters of subjects were taken as control for their after intervention parameters. Blood samples were obtained at the beginning and end of the 90 days of experiment and fasting blood glucose, haemoglobin and lipid (total cholesterol, triglyceride, HDL-cholesterol, LDLcholesterol) levels were measured.

Blood values were analyzed by standard methods at the biochemical laboratory of Thyrocare, Navi Mumbai, a certified clinical laboratory. Blood haemoglobin was analyzed using cyanmeth haemoglobin method (Raghumuralu et al., 2003) and fasting blood glucose (FBG) suing the GOD/POD method of Trinder (1969). Lipid parameters viz. total cholesterol (TC), high-density-lipoprotein cholesterol (HDL-C), triglycerides (TG) and low-density lipoprotein cholesterol (LDL-C) were analyzed using CHOD POD method (Allain et al., 1974), enzymatic selective protection method (Lopesvirella et al., 1977), enzymatic colorimetric method (Buccolo and David, 1973) and homogenous enzymatic colorimetric assay (Sugiuchi et al., 1998), respectively. Very-low-density lipoprotein cholesterol (VLDL-C) was estimated using calculation method (Friedwald et al., 1972).

\section{Intervention design}

A total of 50 postmenopausal hypertensive women enrolled in the study were randomly allocated into two groups - Experimental group A and Experimental group B. Each group consisted of 25 subjects, for whom, the intervention programme was conducted for a period of 90 days. Experimental group A received raw black soybean flour whereas Experimental group B received germinated black soybean flour (50 g in well sealed ziplock pouch/day) for 90 days. Regular monitoring of dietary intervention was done either through home visit or telephone call. All the 50 subjects were examined for general profile, anthropometric measurements, dietary intake, biochemical parameters and blood pressure on zero day. This was followed by supplementation period of ninety days. Four subjects quit in-between the study. Two subjects quit due to their movement to other places, one subject quit due to the some medical reason in between the study and one subject quit because of the taste of the intervention product (black soybean flour) being not liked by her. Finally the dietary intervention was completed by only 46 subjects. On completion of ninetieth day, all the 46 subjects were again examined for biochemical parameters and blood pressure. The baseline parameters of subjects were taken as control for their after intervention parameters.

\section{Statistical analysis}

Data on all parameters viz. general information, food and nutrient intake, anthropometric measurements, physical activity pattern and blood parameters was analyzed statistically. Statistical tools such as mean, standard deviation and standard error were used for detailed analysis. To compare the effectiveness of black soybean flour interventions on the blood parameters and blood pressure, "paired t-test" was applied between the 'baseline' and 'after intervention' values of a parameter of individual subjects. "Two-sample t-test" was used to check significance of difference in the effect of processing treatments (Raw and germinated black soybean flour intervention) between the two experimental groups for various 
parameters i.e. blood pressure, fasting blood glucose, haemoglobin and lipid profile.

\section{Results and Discussion}

Table 1 shows the general characteristics of the subjects. The study included 46 postmenopausal women aged 45-55 years. Majority of the subjects were Hindu $(93.48 \%)$, married $(80.43 \%)$, educated up to post graduation and above $(43.48 \%)$. About $57 \%$ subjects were housewives who were not involved in income generation outside. Majority subjects belonged to nuclear families $(65.22 \%)$ with small family size of 1-4 members $(73.9 \%)$.

The information related to anthropometric measurements, physical activity pattern and hypertension is shown in Table 2 . The mean height $(151.80 \pm 5.64 \mathrm{~cm})$ of subjects was lower than the Indian reference value of 161 $\mathrm{cm}$ (ICMR, 2010) while mean weight was $63.81 \pm 9.80 \mathrm{~kg}$ which is higher than the reference value $(55 \mathrm{~kg})$. The mean BMI of the subjects was $27.70 \pm 4.08 \mathrm{~kg} / \mathrm{m}^{2}$. When classified into various categories of malnutrition on the basis of their BMI (WHO, 2004), majority (58.7\%) of subjects were in the category of pre-obese having BMI in the range of $25-29.99 \mathrm{~kg} / \mathrm{m}^{2}$, followed by $17.4 \%$ women categorized as obese grade I with $\mathrm{BMI}$ in the range of $30-39.99 \mathrm{~kg} / \mathrm{m}^{2}$.

The data on physical activity pattern showed that majority of subjects were having sedentary life style with walking/jogging as the main physical exercise. About $48 \%$ subjects were doing physical exercise daily. The time spent on physical exercise varied from 15 minutes to 45 minutes in majority of the subjects. The mean age of onset of hypertension in subjects was 46.99 \pm 3.50 years, varying with the range of 39 to 53 years. The mean duration of hypertension was observed as $4.37 \pm 2.94$ years among the subjects with the range of 1-13 years. About $46 \%$ subjects had family history of hypertension.

The data on types of therapies used by subjects for the control of hypertension revealed that $76 \%$ subjects were dependent on allopathic medicines. Ayurvedic and homeopathic therapies were being used by 19.6 and $4.3 \%$ subjects, respectively. About $13 \%$ subjects were using traditional medicinal plants like "Harsingar leaves (Nyctanthes arbor-tristis)" and "Punarnava (Boerrhavia diffusa)", known as "Night jasmine" and "hogweed" in English, respectively, for controlling their blood pressure.

Nutrient intake of subjects is given in Table 3 . The findings revealed that subjects of both the experimental groups were comparable for their consumption of all the nutrients, as no statistically significant difference was found between their mean nutrient intakes. Among the micronutrients, dietary fibre intake was found significantly $(\mathrm{p} \leq 0.05)$ higher in the subjects of experimental group B who were supplemented with $50 \mathrm{~g}$ of germinated black soybean flour every day. Energy contribution from carbohydrate, fat and protein was 46, 37 and 17 percent in experimental group $A$ and 45,36 and 19 in the experimental group B.

Table 4 shows the mean change in the haemoglobin level of the subjects before and after the supplementation of two forms of black soybean flour i.e. raw and germinated. The findings on haemoglobin level showed statistically non-significant increase in the mean haemoglobin levels of subjects in both groups. The mean haemoglobin of subjects in groups A and B was 12.28 \pm 0.24 and $12.33 \pm 0.20 \quad(\mathrm{~g} / \mathrm{L})$, respectively, which is normal as per classification of WHO (2017). A non-significant difference was observed in the mean blood haemoglobin level of subjects of both groups $\mathrm{A}$ and $\mathrm{B}$, depicting that raw 
and germinated black soybean flours were almost equally effective in improving blood haemoglobin levels of postmenopausal women.

In the present study, subjects were classified into three categories of diabetes mellitus i.e. normal, pre-diabetic and diabetic, on the basis of their fasting blood glucose level (IDF, 2017). Mean fasting blood glucose was calculated separately for the subjects lying in different categories of diabetes. The findings (Table 5) revealed that there was statistically significant $(p<0.05)$ reduction in the fasting blood glucose levels of pre-diabetic and diabetic subjects of both the groups. On comparison of mean fasting blood glucose levels of two groups, a non-significant difference was observed but the data on percent reduction in mean fasting blood glucose levels with intervention, showed greater improvement in subjects of group B i.e. subjects with dietary intervention of germinated black soybean flour. The reason might be attributed to the higher dietary fibre content of germinated flour in comparison to raw black soybean flour.
Blood pressure of the subjects before and after intervention is presented in table 6 . Findings of the study revealed that dietary supplementation of raw and germinated black soybean flour showed statistically significant $(\mathrm{p}<0.05)$ reduction of 4.49 and $5.4 \%$ in the mean value of systolic blood pressure of groups $\mathrm{A}$ and $\mathrm{B}$, respectively. Similarly, a statistically significant $(\mathrm{p}<0.05)$ reduction of 4.35 and $6.58 \%$ was observed in the mean diastolic blood pressure of groups A and B, respectively.

Data on distribution of subjects in different categories of hypertension showed the shift of subjects from more severe stages of hypertension to the less severe stages with dietary intervention of both raw and germinated black soybean flour.

As evident from figure 2, before dietary supplementation, 68.18 and $58.33 \%$ subjects of groups A and B, respectively, were falling in the categories of stage I hypertension based on systolic blood pressure, which decreased to 36.36 and $50 \%$, respectively, after the dietary intervention. Similar trend was observed in the diastolic blood pressure too (Fig. 3).

Table.1 General characteristics of subjects

\begin{tabular}{|c|c|c|c|}
\hline Characteristic & n $(\%)$ & Characteristic & n $(\%)$ \\
\hline \multicolumn{2}{|l|}{ Religion } & \multicolumn{2}{|l|}{ Occupation of the subject } \\
\hline Hindu & $43(93.5)$ & Employed & $20(43.5)$ \\
\hline Muslim & $3(6.5)$ & Unemployed & $26(56.5)$ \\
\hline \multicolumn{2}{|l|}{ Family type } & \multicolumn{2}{|l|}{ Education } \\
\hline Nuclear & $30(65.2)$ & Illiterate & $4(8.7)$ \\
\hline Joint & $1(2.1)$ & Primary & $7(15.2)$ \\
\hline Extended & $15(32.7)$ & Junior high school & $2(4.3)$ \\
\hline \multicolumn{2}{|l|}{ Family size } & High school & $4(8.7)$ \\
\hline Small (1-4 members) & $34(73.9)$ & Intermediate & $4(8.7)$ \\
\hline Medium (5-8 members) & $10(21.7)$ & Graduation & $5(10.9)$ \\
\hline Large (>8 members) & $2(4.4)$ & Post graduation and above & $20(43.5)$ \\
\hline
\end{tabular}


Table.2 Anthropometric measurements, physical activity pattern and information on hypertension

\begin{tabular}{|c|c|}
\hline Parameters & Value \\
\hline Height (cm) & $151.80 \pm 5.64$ \\
\hline Weight (kg) & $63.81 \pm 9.80$ \\
\hline BMI $\left(\mathrm{kg} / \mathrm{m}^{2}\right)$ & $27.70 \pm 4.08$ \\
\hline \multicolumn{2}{|l|}{ Activity level $\{n(\%)\}$} \\
\hline Sedentary & $42(91.3)$ \\
\hline Moderate & $4(8.7)$ \\
\hline \multicolumn{2}{|l|}{ Type of physical exercise* $\{n(\%)\}$} \\
\hline Walking/Jogging & $34(73.9)$ \\
\hline Yoga/meditation & $20(4.35)$ \\
\hline Cycling & $4(8.7)$ \\
\hline Aerobics & $5(10.9)$ \\
\hline \multicolumn{2}{|l|}{ Frequency of physical exercise $\{n(\%)\}$} \\
\hline Daily & $22(47.8)$ \\
\hline 3days/week & $17(36.9)$ \\
\hline 2days/week & $4(8.7)$ \\
\hline Once/week & $3(6.6)$ \\
\hline \multicolumn{2}{|l|}{ Time spent on physical exercise $\{n(\%)\}$} \\
\hline 15-30 minutes & $13(28.3)$ \\
\hline 30-45 minutes & $17(36.9)$ \\
\hline 45-60 minutes & $9(19.6)$ \\
\hline$>60$ minutes & $7(15.2)$ \\
\hline Age of onset of hypertension (years) & $46.99 \pm 3.50$ \\
\hline Duration of hypertension (years) & $4.37 \pm 2.94$ \\
\hline \multicolumn{2}{|l|}{ Family history of hypertension $\{n(\%)\}$} \\
\hline Yes & $21(45.7)$ \\
\hline No & $25(54.3)$ \\
\hline \multicolumn{2}{|c|}{ Therapy used for hypertension* $\{n(\%)\}$} \\
\hline Allopathic & $35(76.1)$ \\
\hline Ayurvedic & $9(19.6)$ \\
\hline Homeopathic & $2(4.3)$ \\
\hline Traditional medicinal plants & $6(13.1)$ \\
\hline
\end{tabular}

*Multiple responses 
Table.3 Nutrient intake of subjects during the supplementation period

\begin{tabular}{|c|c|c|c|}
\hline Nutrients & Group A & Group B & t-value ${ }^{1}$ \\
\hline Protein (g) & $69.31 \pm 9.84^{2}$ & $72.22 \pm 14.30$ & $\mathrm{NS}^{3}$ \\
\hline Fat $(g)$ & $65.34 \pm 11.77$ & $62.28 \pm 12.83$ & NS \\
\hline Carbohydrates (g) & $181.73 \pm 31.99$ & $175.91 \pm 26.02$ & NS \\
\hline Energy (kcal) & $1592 \pm 233$ & $1553 \pm 266$ & NS \\
\hline Calcium (mg) & $1102.75 \pm 303.37$ & $1066.24 \pm 257.84$ & NS \\
\hline Iron (mg) & $14.39 \pm 2.78$ & $14.90 \pm 2.92$ & NS \\
\hline Beta-carotene $(\mu \mathrm{g})$ & $2519.32 \pm 2332$ & $3162.05 \pm 3961$ & $68.17^{*}$ \\
\hline Vitamin C (mg) & $99.63 \pm 36.29$ & $114.60 \pm 63.41$ & NS \\
\hline Dietary fibre (g) & $46.58 \pm 5.21$ & $49.04 \pm 5.19$ & NS \\
\hline CFP ratio & $46: 37: 17$ & $45: 36: 19$ & \\
\hline
\end{tabular}

${ }^{1}$ statistical significance was calculated by two-sample t-test.

${ }^{2}$ Mean \pm S.E.

${ }^{3}$ Not Significant at $\alpha=0.05$ level by two-sample t-test

${ }^{4}$ CFP ratio is Carbohydrate: Fat: Protein ratio

*Significant at $\alpha=0.05$ level

Table.4 Blood haemoglobin levels $(\mathrm{g} / \mathrm{L})$ before and after intervention

\begin{tabular}{|c|c|c|c|c|}
\hline Groups & Baseline & Final & \% Change & Paired $t$-value \\
\hline Group A $\left(n_{1}=22\right)$ & $12.24 \pm 1.12$ & $12.28 \pm 0.24$ & 0.33 & $0.51^{\mathrm{NS}}$ \\
\hline Group B $\left(n_{2}=24\right)$ & $12.27 \pm 0.24$ & $12.33 \pm 0.20$ & 0.49 & $0.24^{\mathrm{NS}}$ \\
\hline $\mathbf{t}_{\mathrm{AB}}-\mathbf{v a l u e}^{\# \#}$ & $0.26^{\mathrm{NS}}$ & $0.69^{\mathrm{NS}}$ & & \\
\hline
\end{tabular}

Table.5 Effect of dietary intervention on fasting blood glucose levels (mg/dl)

\begin{tabular}{|c|c|c|c|c|}
\hline Groups & Baseline & Final & \% Change & Paired $t$-value \\
\hline \multicolumn{5}{|l|}{ Group A } \\
\hline Normal & $87.76 \pm 3.45$ & $86.74 \pm 4.24$ & 1.16 & $2.08^{\mathrm{NS}}$ \\
\hline Pre-diabetics & $113.27 \pm 7.26$ & $91.89 \pm 6.21$ & 18.88 & $7.26^{*}$ \\
\hline Diabetics & $156.99 \pm 4.65$ & $125.86 \pm 3.98$ & 19.83 & $8.31^{*}$ \\
\hline \multicolumn{5}{|l|}{ Group B } \\
\hline Normal & $91.10 \pm 4.51$ & $88.64 \pm 3.47$ & 2.70 & $2.97^{\mathrm{NS}}$ \\
\hline Pre-diabetics & $107.18 \pm 6.48$ & $91.82 \pm 5.59$ & 14.33 & $4.25^{*}$ \\
\hline Diabetics & $147.79 \pm 5.81$ & $109.89 \pm 4.75$ & 25.65 & $9.67^{*}$ \\
\hline$t_{\mathrm{AB}}$-value ${ }^{1}$ & $0.24^{\mathrm{NS}}$ & $0.29^{\mathrm{NS}}$ & & \\
\hline$t_{A B}-v_{a l u e}{ }^{2}$ & $0.89^{\mathrm{NS}}$ & $0.24^{\mathrm{NS}}$ & & \\
\hline$t_{\mathrm{AB}}-$ value $^{3}$ & $2.25^{\mathrm{NS}}$ & $1.94^{\mathrm{NS}}$ & & \\
\hline
\end{tabular}

*Significant difference at 5\% level, NS: non-significant, ${ }^{1}$ shows comparison between normal subjects of groups A and B, ${ }^{2}$ shows the comparison between pre-diabetic subjects of group A and group $\mathrm{B},{ }^{3}$ shows the comparison between diabetic subjects of group A and group B 
Table.6 Effect of dietary intervention on blood pressure $(\mathrm{mmHg})$ of subjects

\begin{tabular}{|l|c|c|c|c|}
\hline Blood pressure & Baseline & Final & \% Change & Paired $\boldsymbol{t}$-value \\
\hline Systolic & \multicolumn{5}{|l|}{} \\
\hline Group A & $162.70 \pm 4.41$ & $155.40 \pm 3.44$ & 4.49 & $8.50^{*}$ \\
\hline Group B & $157.92 \pm 2.94$ & $149.40 \pm 3.26$ & 5.40 & $11.02^{*}$ \\
\hline $\mathbf{t}_{\mathrm{AB}}$-value & $0.90^{\mathrm{NS}}$ & $1.76^{\mathrm{NS}}$ & & \\
\hline Diastolic & & & & \\
\hline Group A & $98.46 \pm 2.33$ & $94.18 \pm 1.51$ & 4.35 & $5.77^{*}$ \\
\hline Group B & $93.35 \pm 1.22$ & $87.21 \pm 1.06$ & 6.58 & $9.15^{*}$ \\
\hline $\mathbf{t}_{\mathrm{AB}}$-value & $1.94^{\mathrm{NS}}$ & $3.23^{*}$ & & \\
\hline
\end{tabular}

$\mathrm{t}_{\mathrm{AB}}$-value shows comparison between groups A and $\mathrm{B}, *$ Significant difference at $5 \%$ level of significance, NS-Non significant

Table.7 Effect of dietary intervention on lipid profile parameters $(\mathrm{mg} / \mathrm{dl})$ of subjects

\begin{tabular}{|c|c|c|c|c|c|}
\hline Parameter & Groups & Baseline & Final & $\%$ Change & Paired $t$-value \\
\hline \multirow[t]{3}{*}{ TC } & $\mathrm{A}$ & $221.73 \pm 7.89$ & $188.77 \pm 8.04$ & 14.86 & $5.23^{*}$ \\
\hline & B & $224.67 \pm 7.02$ & $183.63 \pm 7.57$ & 18.27 & $6.34^{*}$ \\
\hline & $t_{A B}$-value & $0.28^{\mathrm{NS}}$ & $0.47^{\mathrm{NS}}$ & & \\
\hline \multirow[t]{3}{*}{ HDL-C } & A & $46.19 \pm 1.91$ & $52.55 \pm 2.27$ & 13.77 & $-3.68^{*}$ \\
\hline & B & $52.36 \pm 2.83$ & $58.96 \pm 2.35$ & 12.60 & $-3.40^{*}$ \\
\hline & $t_{A B}$-value & $1.95^{\mathrm{NS}}$ & $1.04^{\mathrm{NS}}$ & & \\
\hline \multirow[t]{3}{*}{ LDL-C } & A & $137.26 \pm 7.79$ & $110.41 \pm 5.99$ & 19.56 & $4.09^{*}$ \\
\hline & B & $134.90 \pm 6.45$ & $113.71 \pm 4.67$ & 15.71 & $5.45^{*}$ \\
\hline & $t_{A B}$-value & $0.23^{\mathrm{NS}}$ & $0.89^{\mathrm{NS}}$ & & \\
\hline \multirow[t]{3}{*}{ TG } & A & $182.89 \pm 22.01$ & $164.59 \pm 9.83$ & 10.01 & $3.49^{*}$ \\
\hline & B & $173.50 \pm 14.25$ & $149.33 \pm 11.78$ & 13.93 & $6.06^{*}$ \\
\hline & $t_{A B}$-value & $0.82^{\mathrm{NS}}$ & $0.11^{\mathrm{NS}}$ & & \\
\hline \multirow[t]{3}{*}{ VLDL-C } & A & $32.05 \pm 6.25$ & $28.31 \pm 2.88$ & 11.67 & $6.62^{*}$ \\
\hline & B & $29.78 \pm 2.47$ & $26.11 \pm 2.46$ & 12.32 & $2.91^{*}$ \\
\hline & $t_{A B}$-value & $0.78^{\mathrm{NS}}$ & $0.52^{\mathrm{NS}}$ & & \\
\hline
\end{tabular}

$\mathrm{t}_{\mathrm{AB}}$-value shows the comparison between group A and group $\mathrm{B}$,

* shows significant difference between values at $5 \%$ level of significance, NS: non-significant 
Fig.1 Study design

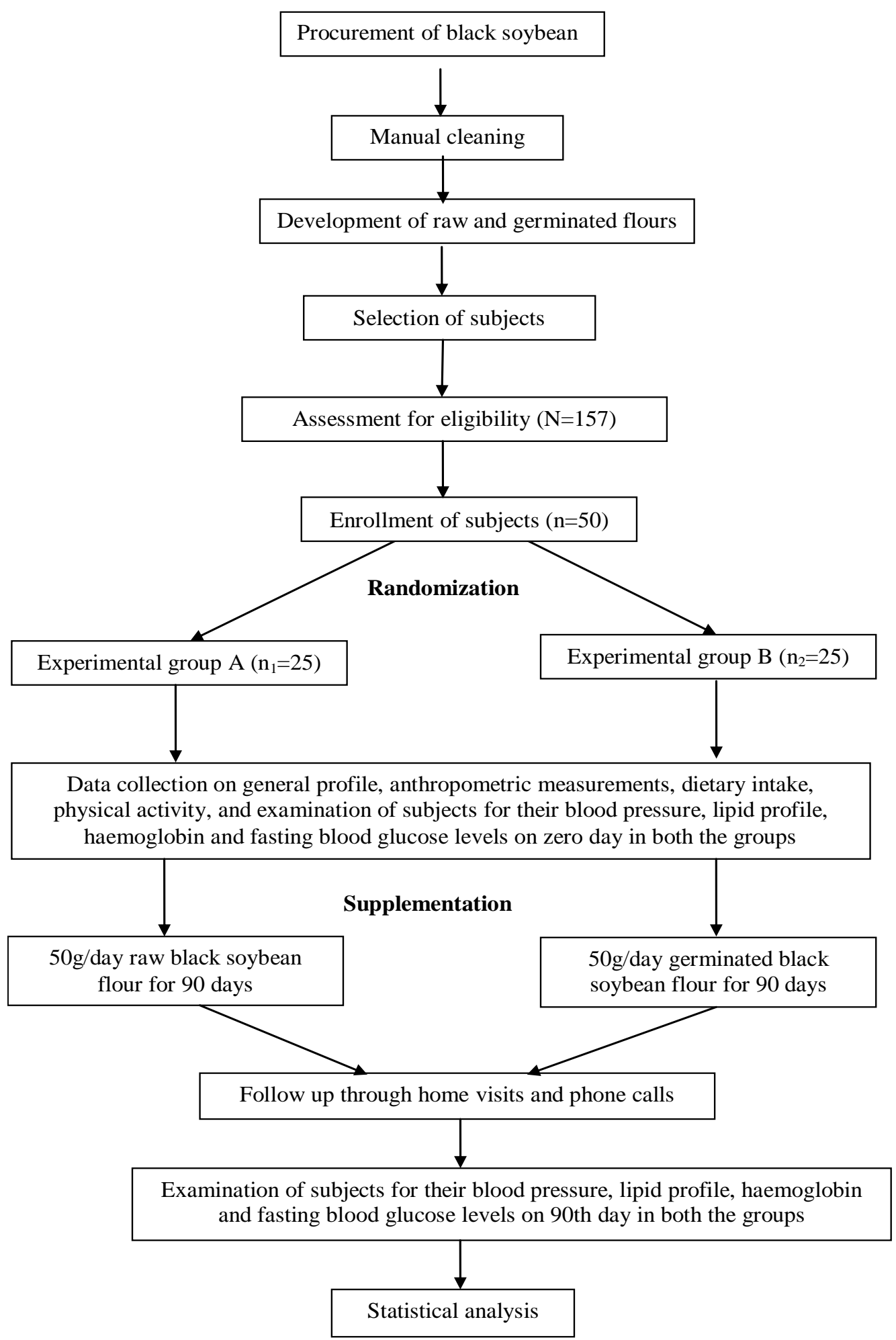


Fig.2 Distribution of hypertensive subjects based on systolic blood pressure

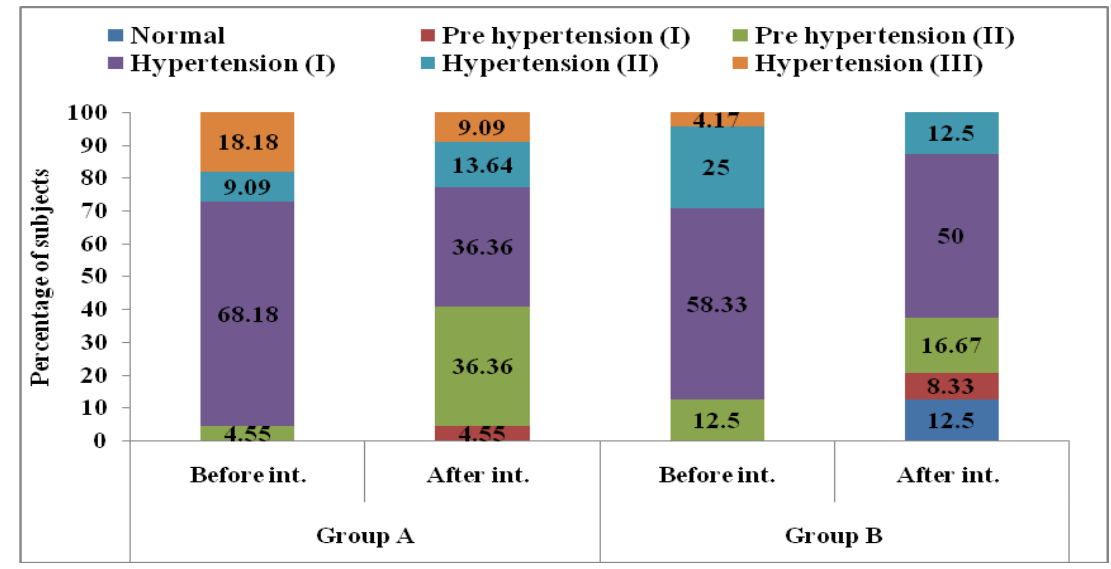

Fig.3 Distribution of hypertensive subjects based on diastolic blood pressure

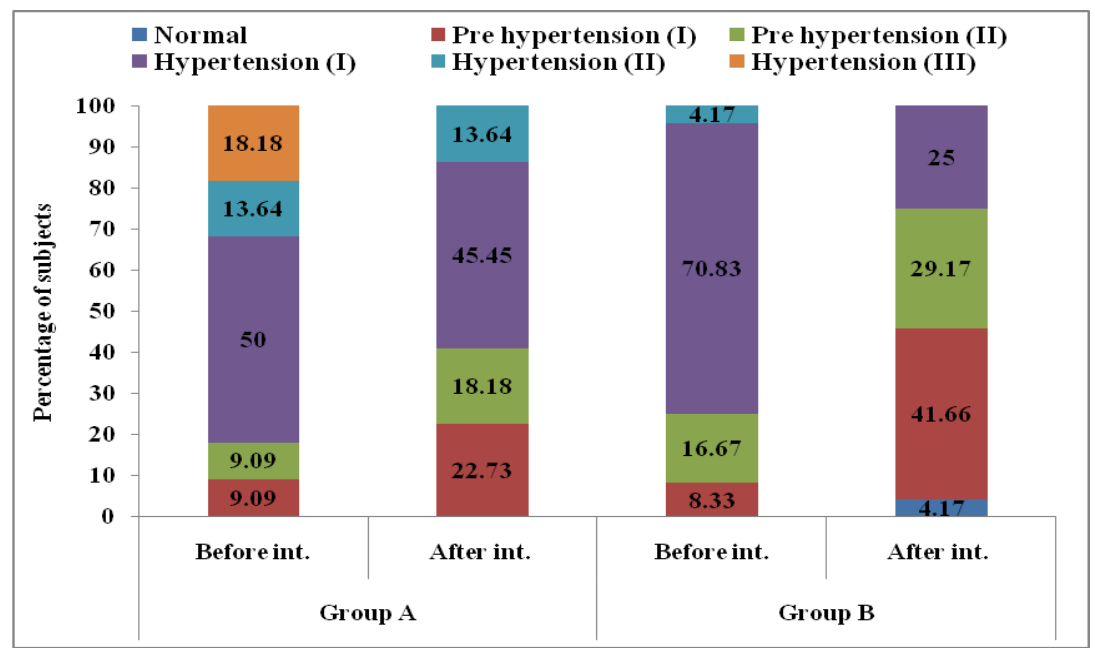

Table 7 shows the effect of dietary intervention on the serum levels of total cholesterol (TC), triglycerides (TG) and lipoprotein fractions. The findings revealed that mean values of TC, HDL-C, LDL-C, TG and VLDL-C showed statistically significant improvements of 14.86, 13.77, 19.56, 10.01 and $11.67 \%$, respectively, in subjects of group A and 18.27, 12.6, 15.71, 13.93 and $12.32 \%$ in subjects of group B supplemented with germinated black soybean flour for 90 days. No statistically significant difference was found between the lipid profile parameters of subjects of groups A and B before or after the dietary intervention.
In the present study, $17.39 \%$ women were categorized as obese grade I. Patel et al., (2016) and Sen and Verma (2016) reported the prevalence of obesity in 61 and $44 \%$ women, respectively. NNMB (2017) in its survey report conducted in various states of the country reported the highest prevalence of overweight in Puducherry (59.8\%), Tamilnadu (54.1\%), New Delhi (52.3\%), Gujarat (52.2\%) and Kerala (52.1\%) while it was lowest in Uttar Pradesh (29.7\%).

More than $90 \%$ subjects of present investigation were having sedentary life style. As per WHO (2002), sedentary lifestyle doubles the risk of cardiovascular diseases, 
diabetes, obesity and increases the risks of colon cancer, high blood pressure, osteoporosis, lipid disorders, depression and anxiety, which are the main causes of mortality in present time. Mansikkamaki (2015) reported that physically inactive women had an increased likelihood of experiencing anxiety, somatic symptoms, memory problems and vasomotor symptoms as compared to the physically active menopausal women. About $46 \%$ subjects reported family history of hypertension. Ranasinghe et al., (2015) showed a strong association of increased risk of hypertension with family history of hypertension in parents, grandparents and siblings.

Gopalan (2007) has recommended energy composition ratio of carbohydrate: protein: fat as 60-65\%: 10-12\%: 15-30\%. In the present study, energy intake of subjects in both the groups was significantly lower than suggested intake. This might be due to the very low mean cereal intake of subjects as $166.57 \pm$ $50.16 \mathrm{~g} /$ day in the present study against the suggested intake of $410 \mathrm{~g} /$ day (ICMR, 2010). In India, carbohydrates derived from the cereals form chief source of energy in the body. Mean dietary fibre intake of subjects in both the groups significantly $(\mathrm{p} \leq 0.05)$ increased to more than $46 \mathrm{~g}$ /day against the suggested intake of $40 \mathrm{~g}$, after the intervention period. The increase could be due to the good amount of dietary fibre in black soybean flour, which was being supplemented in the study (Dobhal, 2018). Dietary fibre reduces the uptake of cholesterol by breaking up the enterohepatic circulation of bile, which results in resynthesis of new bile from the cholesterol (Theuwissen and Mensink, 2008).

One important finding of the present study was that dietary intervention of black soybean flours led to significant $(p<0.05)$ reduction in fasting blood glucose levels of pre-diabetic and diabetic subjects only. Chang et al.,
(2008) also reported a significant reduction in fasting blood glucose and postprandial glucose level in type 2 diabetes mellitus patients intervened with $69 \mathrm{~g} / \mathrm{d}$ of soybean for 4 weeks. Kwon et al., (2010) reported that fermented soybean products had better effect on preventing the progression of type 2 diabetes relative to non-fermented soy products.

The effect of improving glucose levels can be explained by the function of various components of soybean. Soybean fibre contains pectins, galactomannans and arabinogalactans with high viscosity. These substances delay gastric emptying and limit the rate of intraluminal diffusion of glucose absorption in the people with IGT or diabetes mellitus (Holf et al., 1979). The reason for improvement might also be attributed to the isoflavone and anthocyanin content of black soybean which has been reported to have beneficial effect on insulin sensitivity, glucose metabolism and weight reduction after menopause by enhancing energy expenditure and suppressing inflammation (Rios et al., 2015; Kanamoto et al., 2011).

Postmenopausal women have increased risk of developing hypertension, cardiovascular diseases, neurodegenerative disorders, obesity, diabetes mellitus and osteoporosis due to loss of ovarian function and subsequent estrogen deficiency. Isoflavones in black soybean, also known as phytoestrogens, help in reducing the symptoms (Dobhal and Raghuvanshi, 2019) and complications of menopause by mimicking the functions of endogenous estrogen. Shah (2006) also reported the estrogenic activity of black soybean along with its role in preventing ovarian cancers.

The study showed significant improvement in the systolic and diastolic blood pressures of subjects of both the experimental groups. This 
might be attributed to the high crude protein, magnesium and dietary fibre content of black soybean flour, which has been shown to be beneficial in maintaining a healthy cardiovascular system or preventing the CHDs (Singh et al., 1996; Anderson et al., 2009). Various studies have reported the role of isoflavones and anthocyanins of black soybean in improving hypertension and lipid profile (Shah, 2006; Kanamoto et al., 2011). Welty et al., (2007) also reported significant reduction in blood pressure of hypertensive postmenopausal women who consumed soy nuts regularly for 8 weeks.

The present study showed significant improvements in the lipid profile parameters i.e. TC, HDL-C, LDL-C and TG of postmenopausal women. Hanachi and Golkho (2008) reported a significant decrease in TC level of menopausal women with intervention of soymilk containing $12.5 \mathrm{~g}$ of soy protein. Deviga et al., (2016) reported non-significant reduction in $\mathrm{TC}$ values but significant improvement in HDL-C of postmenopausal women with supplementation of yellow soybean flour at the rate of 25 and $45 \mathrm{gm} /$ day in two groups. The reason for the improvement in LDL-C and other lipid profile parameters might be due to the high antioxidant activity of peptides present in black soybean.

Various studies have reported the beneficial role of soybean in management of dyslipidemia (Yang et al., 2017) which is contributed to its high level of flavonoids (Rosa et al., 1998), isoflavones (Messina, 2014) and protein (Liu and Pan, 2011). A meta-analysis of RCTs by Tokede et al., (2015) concluded that consumption of either soy products or soy protein isolate or soy isoflavones for one month to one year, significantly improved lipid profiles in healthy and hypercholesterolemic individuals by lowering circulating TC, TG and LDL-C, and by increasing HDL-C. The comparison of mean values of all lipid profile parameters in experimental groups A and B, didn't show any significant difference which implies that both raw and germinated black soybean flours were equally beneficial in improving lipid parameters in postmenopausal women.

Results of the present investigation suggested a beneficial effect of black soybean flour supplementation on fasting blood glucose levels, blood pressure and lipid profile parameters in postmenopausal women. Black soybean thus may have potential use in the management of dyslipidemia and hypertension in menopausal women. Our study was limited to a small group of subjects, hence for reproducibility, it will be desirable to conduct population-based epidemiological study. Studies can be planned to popularize and commercialize black soybean and its products by improving its processing and designating the product as functional food/nutraceutical.

\section{Acknowledgement}

The authors are thankful to participants without whom this study would not have been possible. We acknowledge our deep sense of indebtedness to the G.B. Pant University of Agriculture and Technology, Pantnagar who permitted us to conduct this study.

\section{References}

Allain, C.C., L.S. Poon and C.S.G. Chan. 1974. Enzymatic determination of total serum cholesterol. Clin Chem. 20: 470-475.

Anderson, J.W., P. Baird, R.H. Davis, S. Ferreri, M. Knudtson, A. Koraym, V. Waters and C.L. Williams. 2009. Health benefits of dietary fibre. Nutr Rev. 67(4): 188-205.

Bhagat, M., S. Mukherjee, and P. De. 2010. 
Clustering of cardiometabolic risk factors in Asian Indian women: Santiniketan women study. Menopause. 17: 359-364.

Buccolo, G., and David, H. 1973. Quantitative determination of serum triglycerides by the use of enzymes. Clin Chem.19: 476-482.

Cano, A., M.A. Garcia-Perez and J.J. Tarin. 2010. Isoflavones and cardiovascular disease. Maturitas. 67: 219-226.

Chang, J.H., M.S. Kim, T.W. Kim and S.S. Lee. 2008. Effects of soybean supplementation on blood glucose, plasma lipid levels, and erythrocyte antioxidant enzyme activity in type 2 diabetes mellitus patients. Nutr Res Prac. 2(3): 152-157.

Chedraui, P., F.R. Perez-Lopez, W. Aguirre, A. Calle and L. Hidalgo. 2010. Beliefs regarding menopausal hot flushes among climacteric women as assessed with the hot flush beliefs scale. Maturitas. 66: 298-304.

Chen, Z., J. Wang, W. Liu W and H. Chen. 2017.

Physicochemical characterization, antioxidant and anticancer activities of proteins from four legume species. J. Food Sci. Technol. 54(4): 964-972.

Chobanian, A.V., G.L. Bakris, H.R. Black, W.C. Cushman, L.A. Green, J.L. Izzo, D.W. Jones, B.J. Materson, S. Oparil, J.T. Wright and E.J. Roccella. 2003. National High Blood Pressure Education Program Coordinating Committee (2003) Seventh Report of the Joint National Committee on Prevention, Detection, evaluation, and treatment of high blood pressure. Hypertension. 42: 1206-1252.

Deviga, T., N.H. Kirubamani and M.B. Naidu. 2016. Effect of soy flour intake on serum lipid profile in postmenopausal women. Int J Pharm Bio Sci. 7(3): 1204-1209.
Dhulkhed, V.K., M.G. Dhorigol, R. Mane, V. Gogate and P. Dhulkhed. 2008. Basic statistical concepts for sample size estimation. Indian J Anaesth. 52(6): 788-793.

Dobhal, N. 2018. Nutritional evaluation and processing of black soybean (glycine max) for its therapeutic effect in ameliorating lipid profile and menopausal symptoms of hypertensive women. Ph.D. Thesis submitted to G.B. pant University of Agriculture and Technology, Pantnagar. 215 pp.

Dobhal, N. and R.S. Raghuvanshi. 2019. Therapeutic Effect of Black Soybean Flour intervention on Menopausal Symptoms of Women. Int. J. Curr. Microbiol. App. Sci. 8(11): 22362252.

Friedwald, W.T., R.I. Levy and D.S. Friedrickson. 1972. Estimation of plasma or serum low density lipoprotein cholesterol concentration without use of preparaline ultracentrifuge. Clin Chem. 18: 499.

Ganesan, K. and B. Xu. 2017. A critical review on polyphenols and health benefits of black soybeans. Nutrients. 9: 455.17 pages.

Gopalan, C., B.V. Ramasastri and S.C. Balasubramanian. 2007. Nutritive value of Indian Foods. National Institute of Nutrition, (ICMR), Hyderabad. 48 pp.

Gupta, R. and D. Xavier. 2018. Hypertension: The most important noncommunicable disease risk factor in India. Indian Heart J. 8 pages.

Gupta, V.K., N. Rai, N.A. Toppo, P.K. Kasar and P. Nema. 2018. An epidemiological study of prevalence of hypertension and its risk factors among non migratory tribal population of Mawai block of Mandla district of central India. Int J Community Med Public Health. 5(3): 957-962. 
Hanachi, P. and S. Golkho. 2008. Assessment of soy phytoestrogens and exercise on lipid profiles and menopause symptoms in menopausal women. J. Biol. Sci. 8: 789-793.

Hipparagi, Y., R. Singh, D.R. Choudhury and V. Gupta. 2017. Genetic diversity and population structure analysis of Kala bhat (Glycine $\max$ (L.) Merrill) genotypes using SSR markers. Hereditas. 154: 9.

Holf, S., R.C. Heading, D.C. Carter, L.E. Prescott and P. Tothill. 1979. Effect of gel fibre on gastric emptying and absorption of glucose and paracetamol. Lancet. 1:636-639.

Hong, S.A. and M.K. Kim. 2017. Relationship between fruit and vegetable intake and the risk of metabolic syndrome and its disorders in Korean women according to menopausal status. Asia Pac J Clin Nutr. 26(3): 514-523.

ICMR. 2010. Nutrient requirements and recommended dietary allowances for Indians. A report of the expert group of the ICMR.

IDF. 2017. International Dietetic Federation clinical practice recommendations for managing Type 2 Diabetes in Primary Care. 36 pp.

Kanamoto, Y., Y. Yamashita, F. Nanba, T. Yoshida, T. Tsuda, I. Fukuda, S. Nakamura-Tsuruta and H. Ashida. 2011. A black soybean seed coat extract prevents obesity and glucose intolerance by up-regulating uncoupling proteins and downregulating inflammatory cytokines in high-fat diet-fed mice. J Agric Food Chem. 59(16): 8985-8993.

Karita, K., Y. Yamanouchi, T. Takano, J. Oku, T. Kisaki and E. Yano. 2008. Associations of blood selenium and serum lipid levels in Japanese premenopausal and postmenopausal women. Menopause. 15(1): 119-24.

Kearney, P.M., M. Wheelton, K. Reynolds, P. Muntner, P.K. Whelton and J. He. 2005. Global burden of hypertension: Analysis of worldwide data. The Lancet. 365: 217-223.

Kou, T., Q. Wang, J. Cai, J. Song, B. Du, K. Zhao, Y. Ma, B. Geng, Y. Zhang, M. Jiang, H. Guo, B. Hu, Z. Li, Y. Zhai and C. Zhang. 2017. Effect of soybean protein on blood pressure in postmenopausal women: a metaanalysis of randomized controlled trials. Food Funct. 8(8): 2663-2671.

Kwon, D.Y., J.W. Daily, H.J. Kim and S. Park. 2010. Antidiabetic effects of fermented soybean products on type 2 diabetes. Nutr Res. 30: 1-13.

Liu, C.F. and T.M. Pan. 2011. Beneficial effects of bioactive peptides derived from soybean on human health and their production by genetic engineering. In: Shemy. H.E. Soybean and health. 2011: pp 311-329.

Lopesvirella, M.F., P. Stone, L. Ellis and J.A. Cohwel. $1977 . \quad$ Quantitative determination of HDL-Cholesterol in serum or plasma by phosphotungustate method. Clin Chem. 23: 882.

Mansikkamaki, K. 2015. Physical activity and menopause-related quality of life: A population-based cross-sectional study. Maturitas. 80(1): 69-74.

Messina, M. 2014. Soy foods, isoflavones, and the health of postmenopausal women. Am J Clin Nutr. 100: 423S$430 \mathrm{~S}$.

NNMB. 2017. Diet and nutritional status of urban women in India and prevalence of obesity, hypertension, diabetes and hyperlipidemia in urban men and women. NNMB Technical Report No. 27. National Institute of Nutrition, Hyderabad.

Patel, P.A., P.P. Patel, B. Yagnik, K. Vora, A. Verma, A.D. Patel, S.A. Chiplonkar 
and A.V. Khadilkar. 2016. Nutritional status assessment of women from different occupations in urban and semi-urban regions of Gujarat. Int $\mathbf{J}$ Food Nutr Sci. 3(2): 381-384.

Penha, L.A.O., I.C.B. Fonseca, J.M. Mandarino and V.T. Benassi. 2007. Soy as food: nutritional value, health benefits and organic cultivation. B.CEPPA. 25(1): 91-102.

Raghuramulu, N., K.M. Nair and S. Kalyanasundaram. 2003. A manual of laboratory techniques. Second edition. NIN, Hyderabad. 421 pp.

Ranasinghe, P., D.N. Cooray, R. Jayawardena and P. Katulanda. 2015. The influence of family history of Hypertension on disease prevalence and associated metabolic risk factors among Sri Lankan adults. BMC Public Health. 15: 576 .

Rios, J.L., F. Francini and G.R. Schinella. 2015. Natural products for the treatment of type 2 diabetes mellitus. Planta Med. 81: 975-994.

Rosa, C.O., N.M. Costa, P.F. Leal and T.T. Oliveira. 1998. The cholesterollowering effect of black beans without hulls in hypercholesterolemic rats. Arch Latinoam Nutr. 48(4): 299-305.

Sen, S. and R. Verma. 2016. Assessment of nutritional status of urban women of Maharashtra, India. IOSR Journal of Nursing and Health Science (IOSRJNHS). 5(1): 1-7.

Shah, N.C. 2006. Black soybean: An ignored nutritious and medicinal food crop from the Kumaon region of India. Asian Agri-History. 10: 33-42.

Singh, R.B., V. Rastogi, M.A. Niaz, J.P. Sharma, R. Raghuvanshi and M. Moshira. 1996. Epidemiological study of magnesium status and risk of hypertension in a rural population of North India. Magnesium Res. 9(3): 173-181.
Sugiuchi, H., T. Irie, Y. Uji, T. Ueno, T. Chaen, K. Uekama and H. Okabe. 1998. Homogeneous assay for measuring low-density lipoprotein cholesterol in serum with triblock copolymer and $\alpha$-cyclodextrin sulphate. Clin. Chem. 44(3): 522-531.

Tandon, V.R., A. Mahajan, S. Sharma and A. Sharma. 2010. Prevalence of cardiovascular risk factors in postmenopausal women: A rural study. J Midlife Health. 1(1): 26-29.

Theuwissen, E. and R.P. Mensink. 2008. Water-soluble dietary fibers and cardiovascular disease. Physiology \& Behavior. 94(2): 285-292.

Tokede, O.A., T.A. Onabanjo, A. Yansane, J.M. Gaziano and L. Djousse. 2015. Soya products and serum lipids: a meta-analysis of randomised controlled trials. Br J Nutr. 114(6): 831-843.

Trinder, P. 1969. Practical clinical biochemistry. Vol X, 5th ed. William Heinnemann Medical Books Limited, New York.

Vanessa, H., J.L. Sievenpiper, R.J. DeSouza, V.H. Jayalath, A. Mirrahimi, A. Agarwal, L. Chiavaroli, S.B. Mejia, F.M. Sacks, M.D. Buono, A.M. Bernstein, L.A. Leiter, P.M. KrisEtherton, V. Vuksan, R.P. Bazinet, R.G. Josse, J. Beyene, C.W.C. Kendall and D.J.A. Jenkins. 2014. Effect of dietary pulse intake on established therapeutic lipid targets for cardiovascular risk reduction: a systematic review and meta-analysis of randomized controlled trials. CMAJ. 186(8): E252-E262.

Welty, F.K., K.S. Lee, N.S. Lew, M. Nasca and J.R. Zhou. 2007. The association between soy nut consumption and decreased menopausal symptoms. J Women Health (Larchmt). 16(3): 361369. 
WHO. 2002. Reducing Risks, Promoting Healthy Lifestyles. The World Health Report. Geneva.

WHO. 2004. Appropriate body-mass index for Asian populations and its implications for policy and intervention strategies. Lancet. 363(9403): 157-163.

WHO. 2017. Nutritional Anaemias: Tools for Effective Prevention and Control. Geneva: World Health Organization; 2017.

Yang, Q., C. Song, J. Jiang, Y. Chen, S. Liang, S. Ma, K. Dong, W. Nie and K. Wang. 2017. Association of reproductive history with hypertension and prehypertension in Chinese postmenopausal women: a populationbased cross-sectional study. Hypertens Res. 41: 66-74.

Zhoua, Y., X. Zhoua, X. Guoa, G. Suna, Z. Li, L. Zheng, H. Yanga, S. Yua, W. Li, L. Zoua and Y. Suna. 2015. Prevalence and risk factors of hypertension among pre and postmenopausal women: A cross-sectional study in a rural area of northeast China. Maturitas. 80: 282-287.

\section{How to cite this article:}

Neetu Dobhal and Rita Singh Raghuvanshi. 2020. Effect of Black Soybean (Glycine max (L.) Merrill) Flour Intervention on Blood Pressure, Fasting Blood Glucose Level and Lipid Profile of Hypertensive Postmenopausal Women. Int.J.Curr.Microbiol.App.Sci. 9(09): 476-492. doi: https://doi.org/10.20546/ijcmas.2020.909.061 